\title{
Eco Green Campus: Challenges and Opportunities. The Study Case of Polytechnic Institute of Beja
}

\author{
Ana Pardal $^{1,2^{*}}$, Telma Romeira ${ }^{1}$, Anabela Durão ${ }^{1,3}$ \\ ${ }^{\text {I} P o l y t e c h n i c ~ I n s t i t u t e ~ o f ~ B e j a, ~ R u a ~ P e d r o ~ S o a r e s, ~ C a m p u s ~ d o ~ I P B e j a, ~ 7800-295 ~ B e j a, ~ P o r t u g a l ~}$ \\ ${ }^{2}$ FiBenTech - Fiber Materials and Environmental Technologies, Universidade da Beira Interior, Portugal \\ ${ }^{3}$ ICT - Instituto de Ciências da Terra, Universidade de Évora, Portugal
}

\begin{abstract}
Higher Education Institutions have an important role in the promotion of sustainability. The sustainability has been seen not only as a component of education, research and innovation, but also as a social learning process within and beyond academia. The adherence of the four schools that belongs to IPBeja, to the Eco-Schools Program allows the environmental analysis of each. The present work intends to contribute to the creation of the Eco Green Campus in to Polytechnic Institute of Beja (IPBeja). Environmental audits were carried out on the four Schools and in the IPBeja common services facilities. The results shows that it is necessary to implement some measures in order to IPBeja become an Eco Green Campus, involving all academic community: improvement of resource management; reduction of waste and effluent production; waste recovery; reduction of water and energy consumption; use of renewable energy; promotion of sustainable mobility and adoption of sustainable public procurement. It was proposed a concept of an Eco Green Campus, the IPBeja Environmental Policy and Environmental Best Practices Guide, oriented for decision-makers and for the entire academic community. The creation of an Eco Green Campus is simultaneously a challenge and an opportunity to contribute and promote the Circular Economy.
\end{abstract}

\section{Introduction}

There were several motivations for this work: the goal of walking towards a Sustainable development; the National Education Strategy, approved in 2017; the "Circular Economy" concept and finally several Universities are experiencing a growing trend to redefine their strategies and organisations along the lines of sustainability and there are several examples of Sustainable Campus.

Sustainability is an issue that has been present in many official agendas in private, governmental, and educational sectors. However, the progress towards the goals established in Rio de Janeiro has been slower than it was hoped. Throughout the course of the years, there have been some institutions that have taken and followed plans of action to successfully promote sustainability initiatives, while other's sustainability initiatives have ceased to continue because of lack of support on the campus where they were implemented.
What is missing is a clear orientation on exactly what a sustainable university should be [1].

Perhaps the most important issue for survival in our times is how to sustain the natural environment and our planets resources at the same time as develop wealth and well-being for a growing population. This monumental task has been defined in the concept of sustainable development (SD). During the last few decades the world communities have, under the umbrella of the UN, agreed upon jointly addressing SD. As a response, Education for Sustainable Development (ESD) has been launched as one of the key answers to dealing with sustainability [2].

Velaquez et.al defined sustainable university as "A higher educational institution, as a whole or as a part, that addresses, involves and promotes, on a regional or a global level, the minimization of negative environmental, economic, societal, and health effects generated in the use of their resources in order to fulfill its functions of teaching, research, outreach and 
partnership, and stewardship in ways to help society make the transition to sustainable lifestyles" [1].

Universities have been considering sustainability as an issue of their responsibility and a subject for management since the 1970s. However, it wasn't until after the Talloires Declaration in 1990 that a large number of universities formalized their commitment to act in favor of sustainable development by signing many other treaties. The leadership of European universities in the study of sustainability in higher education is well recognized, nevertheless, there are reports of experiences and contributions from many other parts of the world. Despite the relative consensus that the sustainability model is based on a three-pillar approach (environmental, economic and social), sustainability is still a controversial concept as it may reflect different ways to address the relationship between humanity and the environment [3].

In the last two decades there has been a growing consensus that universities are strategic agents in the promotion of sustainability. Several aspects support this proposition, including the need to reduce the environmental impact of their activities, the fact that they are institutions that promote innovation, their role on the education of leaders, teachers and distinct professionals who influence society, and their impact on regional sustainable development [3].

However, campus sustainability initiatives stumble upon many impediments, most of which are related to the low precedence of environmental issues on the campus agenda and are compounded by a lack of coordination between and among activists and key communities. To some, a sustainable campus is just having master plan, environmental plan and guidelines or environmental statement while others may believe that they may have met the challenge of sustainability through signing of national o international declarations. Reactive responses through adhoc programs and behaviours may steer to an inefficient and may not assure sustainability.

Sustainability issues are becoming complex, multidimensional and interconnected and required an integrated and systematic approach to decisions making, investment and management processes. The first issue concerning the FM practices and implementation towards sustainability within the institution of higher learning is a vital element in this research. The main issue therefore concentrates on the degree or extent of implementation and practices of FM effectiveness within this institution of higher learning. In summary, the intricate and complex processes require systematic implementation to attain ultimate effectiveness to ensure sustainability objective is achieved [4].

The Sustainable Development Goals are the blueprint to achieve a better and more sustainable future for all. They address the global challenges we face, including those related to poverty, inequality, climate change, environmental degradation, peace and justice. The 17 Goals are all interconnected, and in order to leave no one behind, it is important that we achieve them all by 2030. Click on any specific Goal below to learn more about each issue [5].

The adoption of a National Education Strategy (ENEA 2020) for the period 2017- 2020 is a major challenge for our common future. The National Strategy for Environmental Education aims to establish a collaborative, strategic and cohesive commitment in the construction of environmental literacy in Portugal, through an inclusive and visionary citizenship that leads to a change of civilizational paradigm, translated into sustainable models of conduct in all dimensions. of human activity. The implementation of this Strategy foresees 16 measures framed by 3 strategic objectives: Environmental Education and Cross Education, Environmental Education and Open and Environmental Education and Participation [6].

The concept of the circular economy reflects the recognition that European systems of production and consumption need to be fundamentally transformed to achieve the EU's 2050 vision of 'living well within the limits of our planet' [7].

The Eco-Schools programme is an ideal way for schools to embark on a meaningful path towards improving the environmental footprint of a school, a change which inevitably leads to a more sustainable, less costly and more responsible school environment. 
Eco-Schools challenges students to engage in tackling environmental problems at a level where they can see tangible results, spurring them on to realise that transmission and dissemination of culture and knowledge of a professional nature, targeted research and experimental development, concentrated especially

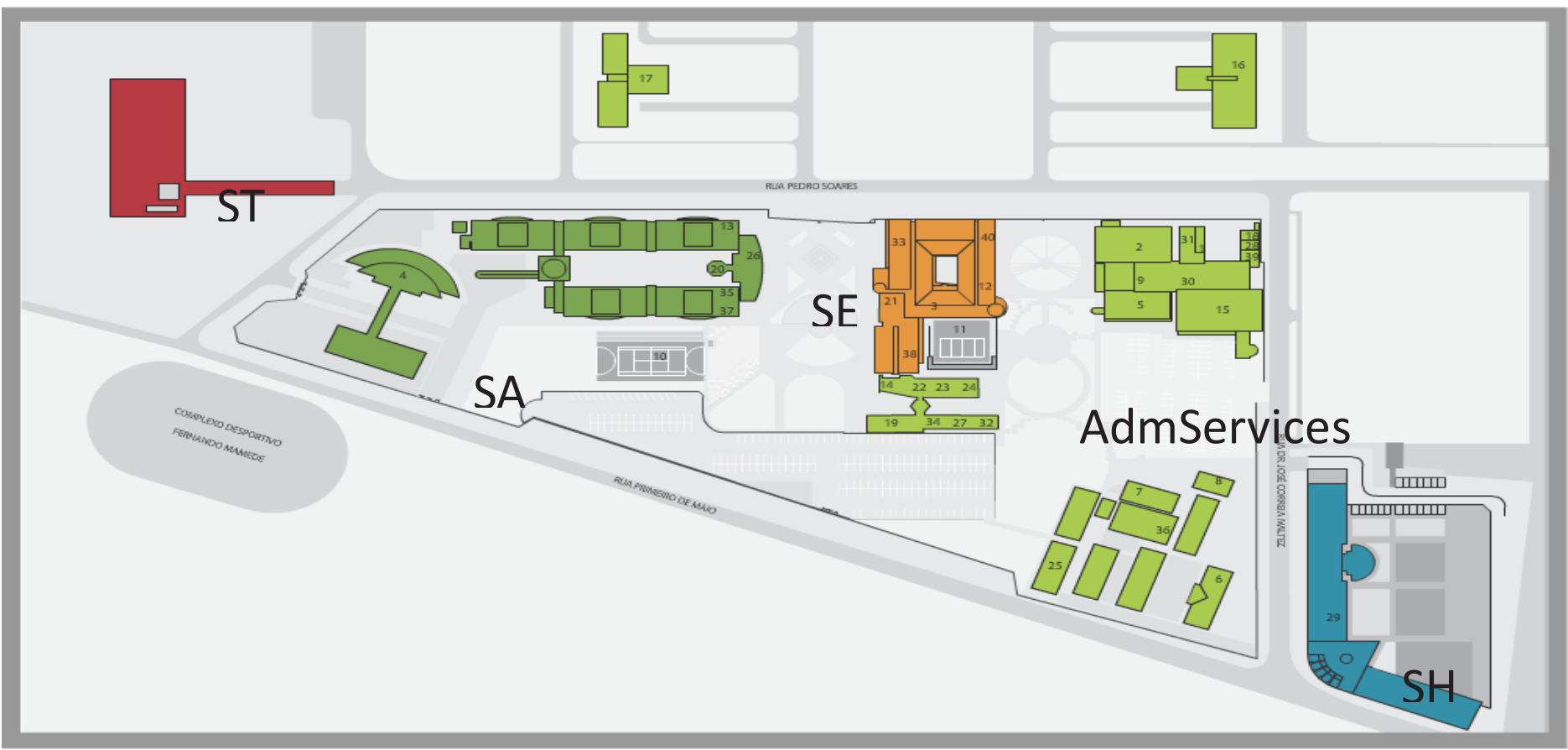

Fig. 1. IPBeja main campus

they really can make a difference [1].

The Eco-Schools Seven Steps methodology is a series of carefully engineered measures to help schools to maximise the success of their Eco-School ambitions. The method involves a wide diversity of individuals from the school community - with students playing a primary role in the process [9]. It is a certification program within which schools can earn a 'green flag', based on external evaluation. Overall, the project aims to improve the environment through direct and indirect effects. Direct effects are those that can be labeled as, for example, increased biodiversity on campus, more recycling or more waste prevention, more energy efficient solutions in schools, etc. Indirect effects are those that are realized through the impact that the project has on the students: an increase in their environmental attitudes, better decision-making skills, more motivation to make a difference, etc. [10].

\subsection{Polytechnic Institute of Beja}

The Polytechnic Institute of Beja (IPBeja) is a Higher Education institution created in 1979, located in the city of Beja, Portugal.

The Polytechnic Institute of Beja is a higher education institution in service of society, for the production and dissemination of knowledge creation, in formations vocational and advanced technical training, professionally oriented and encouraging lifelong.

IPBeja includes four Schools - the School of Agriculture (SA), the School of Education (SE), the School of Technology and Management (ST) and the School of Health $(\mathrm{SH})$, with a range of more than 30 courses on offer, including "Short-Cycle" (Higher Vocational Technical Courses), Bachelor's Degrees, Master's Degrees, Post-Graduate Studies and others [11].

Although IPBeja has other, facilities, including residences, experimental centers, this work focused on the main campus (Fig 1).

In $t 2017 / 18$ Academic year, the academic community consisted of 256 teachers, 135 nonteaching staff and 2,537 students, a total of 2928.

\section{Methodology}

The Environmental Review carried out by the EcoSchools Committee was analysed. New Environmental Review were carried out, in order to confirm some results and fill in some gaps, this last results are presented in this paper. 
To perform the Environmental Review of IPBeja Schools and Administrative Services, the Eco-Schools Program Environmental Audit Guide [12] was followed, with some changes since it is more focused to pre-school education and also to first cycles of education. In addition to the basic themes of the EcoSchools program (waste, energy and water), this Review also covered the topics "Outdoor spaces", "Mobility", "Food" and "Environmental Management".

Some measures were proposed to implement at IPBeja to become an Eco Green Campus. It was also proposed an Environmental Policy and a Guide of fluorescent lamps fuse they are replaced by LED lamps. A positive example of natural light is found in ST, where there are skylights that allow the entrance of natural light (figure 2 a).

In all school buildings there are some kind of "light cut" either blinds or curtains, as can be seen in figure 2 b. In almost building entrances are dustbins with ashtrays (figure 2c). There is some reuse of rainwater in the SH (figure 2c) to perform splints in the Occupational Therapy Degree.

Up to the current data, was observed that IPBeja does not do "Green Public Procurement" (green
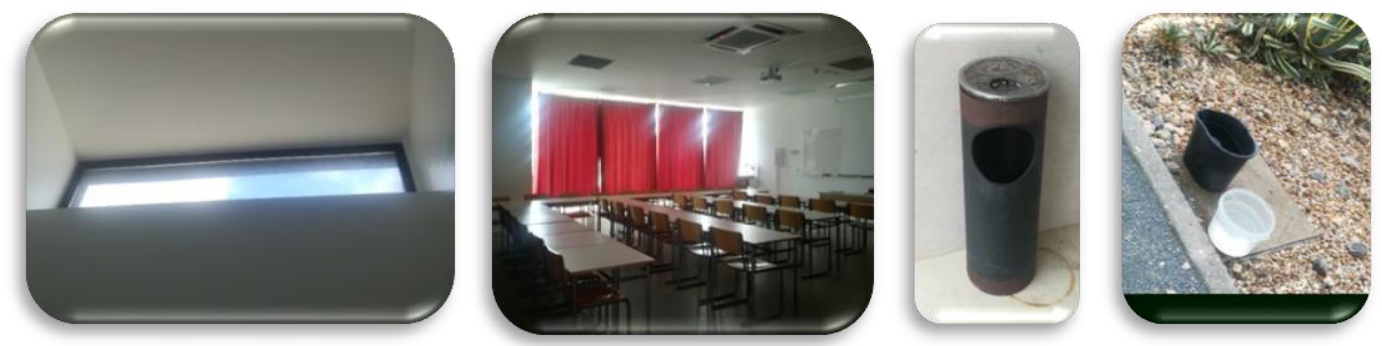

Fig. 2. (a) Skylight at School of Technology and Management; (b) Curtains at School of Education; (C) Dustbins with ashtrays; (d) Rainwater collection at School of Health

\section{Good Environmental Practices}

Since there are several concepts, with different definitions to describe the concept of Higher Education Campus that have implemented measures of Good Environmental Practices, in this work it is propose a concept of Eco Green Campus.

\section{Results}

\subsection{Characterization of Polytechnic Institute of Beja}

The school buildings (except ST) and facilities of IPBeja Campus are around 20 years old of construction. The visual observation of the buildings shows that they have a good state of preservation, although there are some occasional episodes (infiltration) that need intervention.

The main source of energy in IPBeja Campus is electricity and fuels for IPBeja's fleet. Gas (propane and natural) is also used at SA, SE and Administrative Services I, particularly in the canteen. To date, IPBeja has no renewable energy source.

Regarding to lighting it consists essentially of natural lighting and fluorescent lamps, however, when procurement is preferable for procurement of products and materials, considering the environmental impacts and / or choice of suppliers in accordance with its environmental activities). It does not seem to be a concern of IPBeja, the purchase of products and services, the choice of suppliers with environmental management systems, or the choice of "environmentally friendly" products, for example when buying detergents or recycled paper. However, cartridge purchases are no longer verified because recycled ink cartridges are purchased.

\subsection{Water, electricity and gas consumption}

Tables 1, 2 and 3 show the consumption of water, electricity and gas at IPBeja Campus, from 2016 to August 2018, respectively. The meter of electricity, related to SE serves also the administrative services

The water consumption has been decreasing in SA, SE, especially in ST (Table 1), due to the awareness campaigns performed. The highest water consumption is observed at SA followed by Administrative Services which is justified by the laboratory activities and the canteen, respectively. 
Table 1 - Water consumptions $\left(\mathrm{m}^{3}\right)$ by school (SA, ST, SE, $\mathrm{SH}$ and Administrative services) during the monitoring period (from 2016 to August 2018)

\begin{tabular}{|c|c|c|c|c|}
\hline $\begin{array}{c}\text { Water } \\
\mathbf{( m}^{\mathbf{3}} \mathbf{)}\end{array}$ & $\mathbf{2 0 1 6}$ & $\mathbf{2 0 1 7}$ & $\begin{array}{c}\mathbf{2 0 1 8}- \\
\text { Aug. 2018 }\end{array}$ & Total \\
\hline SA & 2918 & 2498 & 2258 & 7674 \\
\hline ST & 1270 & 749 & 409 & 2428 \\
\hline SE & 779 & 620 & 489 & 1888 \\
\hline SH & 666 & 668 & 755 & 2089 \\
\hline $\begin{array}{c}\text { Adm } \\
\text { Services }\end{array}$ & 1428 & 1999 & 2024 & 5451 \\
\hline Total & 7061 & 6534 & 5935 & - \\
\hline
\end{tabular}

Regarding to electricity consumption the $\mathrm{SH}$ highlights the lower consumption, which is explained by the size of this school and also by the internship periods of the courses taught there (Table 2). There is a decrease in electricity consumption in all buildings except in SA.

Table 2 - Electricity consumptions (KWh) by school during

\begin{tabular}{|c|c|c|c|c|}
\hline $\begin{array}{c}\text { Electricity } \\
\text { (kWh) }\end{array}$ & $\mathbf{2 0 1 6}$ & $\mathbf{2 0 1 7}$ & $\begin{array}{c}\text { 2018- } \\
\text { Aug. 2018 }\end{array}$ & Total \\
\hline SA & 397426 & 421814 & 261834 & 1081074 \\
\hline ST & 222285 & 205416 & 143778 & 571479 \\
\hline SH & 87250 & 78108 & 55943 & 221301 \\
\hline $\begin{array}{c}\text { SE + } \\
\text { Admin } \\
\text { services }\end{array}$ & 440973 & 410787 & 286242 & 1138002 \\
\hline Total & 1147934 & 1116125 & 747797 & \\
\hline
\end{tabular}

the monitoring period (from 2016 to August 2018)

There is irregular gas consumption at SA (ESA) (Table3), which can be justified by laboratories activities that contribute significantly to these consumptions. In the SE and AdmServices from 2016 to 2018 there is a trend of increasing consumption, quite significant (Table 3).

Table 3 - Gas consumptions by service/school during the monitoring period (from 2016 to August 2018)

\begin{tabular}{|c|c|c|c|}
\hline Gas & SA $\left(\mathbf{m}^{\mathbf{3}}\right)$ & SE $(\mathbf{k g})$ & $\begin{array}{c}\text { AdmServices } \\
\left.\mathbf{( m}^{\mathbf{3}}\right)\end{array}$ \\
\hline $\mathbf{2 0 1 6}$ & 961 & 2146 & 10134 \\
\hline $\mathbf{2 0 1 7}$ & 2105 & 2205 & 8951 \\
\hline $\begin{array}{c}\mathbf{2 0 1 8} \text { (until } \\
\text { August) }\end{array}$ & 19 & 3192 & 11955 \\
\hline Total & 3085 & 7543 & 31040 \\
\hline
\end{tabular}

\subsection{Environmental Review}

Figure 3 depicts the main results of the Environmental Reviews. These values reports the average value obtained in each theme studied and the results of the

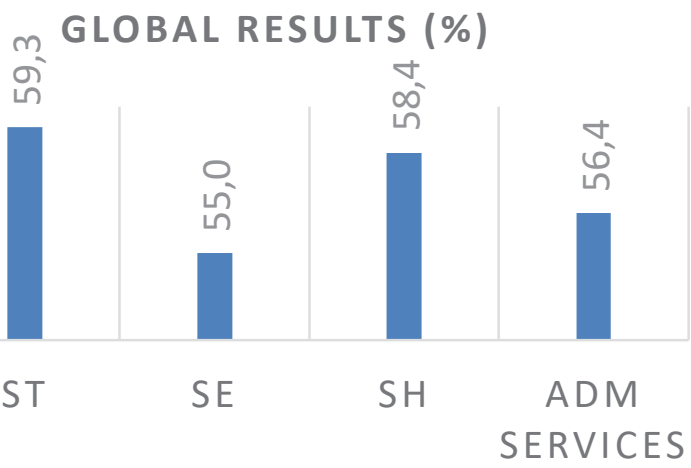

Fig. 3. Global Indexes Results of Environmental Audits conducted in the 2017/18 School Year

surveys applied to the students. The best performing belongs to ST (59\%) and the lowest (55\%) belongs to SE, although the differences are not significant.

The results regarding the basic themes (water, waste, energy) are shown in figure 4 . The best performing belongs to ST and the lowest belongs to $\mathrm{SA}$, which can be explained by the higher consumptions, observed in Table 1, 2 and 3.

The highest value result is considered as the best results of environmental audit, representing the work developed by school through Eco-School program concerned to environmental sustainability and also the specific characteristics of each school building.

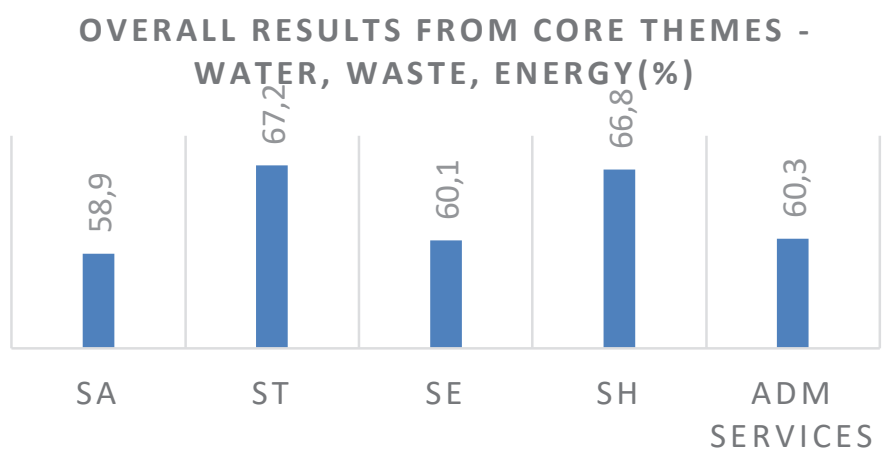

Fig. 4. Indexes Results of Environmental Audits regarding the basic themes (water, waste and energy) conducted in the 2017/18 School Year. 
IPBeja joined the U-bike Portugal Project [13] which aims to promote smooth mobility and the adoption of sustainable mobility habits in higher education academic communities. IPBeja's operation involves a total of 200 bicycles, 80 electric and 120 conventional.

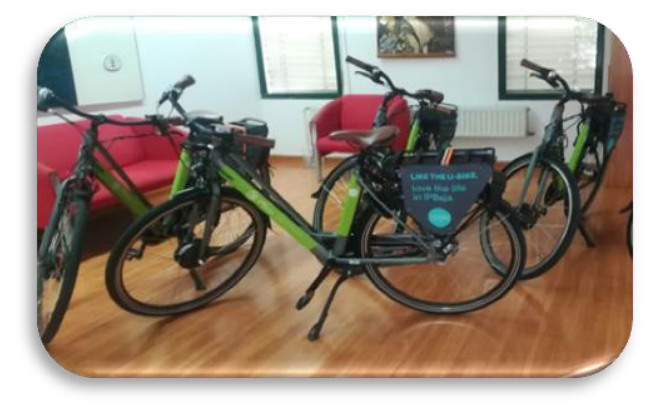

Fig. 5. IPBeja Bike

\subsection{Suggestion of measures to be implemented in order to IPBeja become an Eco Green Campus}

It is necessary to make some changes / improvements, based essentially on better resource management, reduction of waste, waste recovery and use of renewable energy, for IPBeja to become an Eco Green Campus.

The actions to be implemented (short, medium and long term) are described by theme. Regarding water theme the action can be: (1) installation water pressure at the bulging in order to avoid the increase of water consumption; (2) use the water from tap in meeting, conferences, seminar (3) acquisition of tap water dispenser; (4) control and minimize the water waste; (5) periodical maintenance (tap, toilet flush, valves); (6) rainwater reuse, eg for use in irrigation systems.

Nowadays it is common to speak about Zero Waste, where the main objective (is not to send anything to the landfill) is based on a set of practices to avoid waste, namely the implementation of $5 \mathrm{R}$ 's of zero waste (Refuse, Reduce, Reuse, Recycle, Rot), that promote the circular economy. The action for waste theme can be: (1) eco points placement throughout IPBeja; (2) organic separation for waste recovery (composting); (3) purchase of glass jars and cups for seminars or academic events; (4) formatting printers to print by default on two-sided and in black and white; (5) count paper consumed (number copies and print) per month in all services; (6) periodic inspection of waste collection containers.
Regarding energy theme the action can be: (1) placement of LED in all campus and installation of presence sensors; (2) periodic maintenance of buildings, namely blinds and lamps; (3) acquisition of electric vehicles; (4) placement of sockets for charging electric vehicles; (5) observation of energy efficiency standards, adopting values significantly lower than $10 \mathrm{~W} / \mathrm{m}^{2}$ for lighting, taking into account the gross floor area of buildings; (6) to obtain Energy Certification; (7) efficiency of Heating improvement, Ventilation and Air Conditioning (HVAC) systems with the implementation of consumption control and mitigation measures.; (8) use renewable energy.

Green Public Procurement (GPP) is an important instrument for achieving environmental policy objectives related to climate change, resource use and sustainable consumption and production. It is recommended to use the European Commission Handbook [14]. The Handbook is the European Commission's main guidance document to help public authorities buy goods and services with a lower environmental impact. It is also a useful reference for policy makers and companies responding to green tenders.

The Environmental Management System (EMS) is a voluntary environmental policy instrument aimed at continually improving environmental performance and enabling the organization's management bodies to better control the activities and processes that promote negative impacts on the environment [15]. It is recommended the implementation of the EMS at IPBeja Campus. This could be achieved through a sustainability report, which would list and analyse the environmental, social, economic and cultural impacts of IPBeja's activity.

Training/information actions are considered important to be developed for the entire academic community regarding: environmental issues to achieve the aims of an Eco Green Campus; Environmental Audits namely in NP EN ISO 14001 Standard. It is also recommended to include the Eco-Schools Program in the IPBeja Educational Program.

\subsection{Guide of Good Environmental Practices}

The aim of the Guide of Good Environmental Practices is to promote the sense of responsibility towards the environment, includes the proposal of the Environmental Policy to the IPBeja and several areas were covered, such as water consumption control in order to minimize the costs; (2) waste solids 
management to minimize the production of the various waste categories and their proper management in order to close de cycle and promote circular economy; (3) energy consumption control in order to minimize the costs; (4) sustainable mobility to reduce pollutant emissions; (5) wastewater from domestic and laboratory activities to avoid pollution; (6) Practices for conscious use of chemicals. The advantages of its implementation are: decrease the consumption of resources, water, energy; reduce costs associated with water, energy, fuel consumption, drainage network conservation and waste management; ensure compliance with current legislation; reduce wastewater production and minimise the environmental impact, reduce the amount of landfilled waste and greenhouse gas emissions; avoid pollution of water, soil, odour release, visual; stimulate physical exercise; avoid damage to public health.

Environmental Policy promotes: the continuous improvement of the environmental performance of its activities, always with a view to the sustainable use of environmental resources and pollution prevention; the improvement waste management through reduce, reuse and recycling measures (3 R's policy); the reduction of water waste and energy consumption; to meet applicable legal requirements and other subscribed conditions regarding environmental aspects; to Incorporate eco-management practices into the Department activities and support services sectors within IPBeja and stimulate the improvement of its environmental and sustainability performance; the identification of environmental objectives, targets and evaluate their implementation annually; awareness and involvement of the academic community and certify the commitment of other entities that coexist in IPBeja to continuously improvement of their environmental performance.

\subsection{Concept of an Eco Green Campus}

The concept of an Eco Green Campus is a Campus that, has the aim of achieving sustainable development, has a culture of sustainable use of resources, nature conservation, pollution prevention, promotion of behaviour and attitudes changes, commitment participation and engagement of the academic community.

The Eco Green Campus main lines action should be: implementation of Best Environmental Practices; education; investigation; internal and external community engagement; communication, information and public participation; implementation of an Environmental Management System.

\section{Final remarks}

The results of this study shows that it is necessary to implement some measures in order to IPBeja become an Eco Green Campus, involving all academic community.

Detailed monitoring of consumption allows setting tangible targets for reducing them.

Some measures suggested are: improvement of resource management; reduction of waste and effluent production; waste recovery; reduction of water and energy consumption; use of renewable energy; promotion of sustainable mobility and adoption of sustainable public procurement.

The practices for conscious use include a set of practical, useful and didactic actions that serve to modify or improve usual behaviours and aim to: optimize and reduce the consumption of natural resources (water, energy); decrease the production of contaminants (gas emissions to the atmosphere, soil and/or water contamination); minimize and properly manage waste production; raise awareness and educate the entire academic community with realization: of awareness campaigns, seminar/ workshops, etc.

The sustainability has been seen not only as a component of education, research and innovation, but also as a social learning process within and beyond academia.

The creation of an Eco Green Campus seems to be simultaneously a challenge and an opportunity to contribute and promote the Circular Economy.

\section{Acknowledgements}

Publication is funded by the Polish National Agency for Academic Exchange under the International Academic Partnerships Programme from the project „Organization of the 9th International Scientific and Technical Conference entitled Environmental Engineering, Photogrammetry, Geoinformatics - Modern Technologies and Development Perspectives".

\section{References}

1. L. Velazquez, N. Munguia, A. Platt, J. Taddei, Sustainable university: what can be the matter? 
Journal of Cleaner Production. 14: p. $810-819$ (2016)

2. J. Boeve-de Pauw, N. gericke, D. Olsson, T. berglund, The Effectiveness of Education for Sustainable Development. Sustainability. 7(11): p. 15693-15717 (2015)

3. M. Bizerril, M.J. Rsa, T. Carvalho, J. Pedrosa, Sustainability in higher education: A review of contributions from Portuguese Speaking Countries. Journal of Cleaner Production. 171: $\mathrm{p}$. 600-612 (2018)

4. A.A. Saleh, N. Kamarulzaman, H. Hashim, S.Z. Hashim, An Approach to Facilities Management (FM) Practices in Higher Learning Institutions to Attain a Sustainable Campus (Case Study: University Technology Mara - UiTM). 2nd International Building Control Conference, 20 (2011)

5. U. Nations, The Sustainable Development Goals Report (2019)

6. APA (Portuguese Environment Agency), National Environmental Education Strategy - ENEA2020 (2019).

7. E.E. Agency, Circular economy in Europe Developing the knowledge base. Luxembourg: Publications Office of the European Union (2016)

8. Foundation for Environmental Education. EcoSchools, [cited 2019 15/11/2019]; Available from: https://www.ecoschools.global/how-does-it-work

9. Foundation for Environmental Education. Seven Steps - Eco-Schools, [cited 2019 15/11/2019]; Available from: https://www.ecoschools.global/seven-steps

10. J. Boeve-de Pauw, P. Van Petegem, Eco-school evaluation beyond labels: the impact of environmental policy, didactics and nature at school on student outcomes. Environmental Education Research. 24(9): p. 1250-1267 (2018)

11. IPBeja. Instituto Politécnico de Beja. 2011 [cited 2019 15/11/2019]; Available from: https://www.ipbeja.pt/en/Pages/default.aspx.

12. ABAE. Guia de Auditoria Ambiental. 2013

13. IMT. U-Bike Portugal. 2017 [cited 2019 21/11/2019]; Available from: https:/www.ubike.pt/instituicoes/
14. European Commission, Buying green!A handbook on green public procurement $3 r d$ Edition, ed. E. Union (2016)

15. Santos, F.M., Benchmarking Ambiental e de Sustentabilidade para Campus Universitários Caso de Estudo FCT-UNL. Lisboa: Universidade Nova de Lisboa (2009) 